\title{
O BAUDELAIRE DE FOUCAULT: UMA SILHUETA FURTIVA E PARADOXAL ${ }^{1}$
}

\author{
Philippe Chevallier* \\ Biblioteca Nacional da França
}

\author{
Tradução de Pedro de Souza \\ Universidade Federal de Santa Catarina
}

\begin{abstract}
Resumo: Personagem fugidio, o Baudelaire de Foucault tem uma vida ao mesmo tempo breve e notável. Breve, porque um único texto em 1984 lhe oferece um espaço de expressão consequente. Notável, porque esse texto é a ocasião de um deslocamento importante dos próprios pressupostos filosóficos de Foucault sobre as relações da subjetividade com a história. A contrapelo de um corte na história em periodos radicalmente heterogeneos, tal como o apresenta, por exemplo, As palavras e as coisas, em $1966^{2}$, a silhueta de Baudelaire desenha a possibilidade da remanência ${ }^{3}$, através das eras culturais distintas, de uma mesma atitude subjetiva prova que a história da subjetividade não conhece os mesmos cortes que a história dos poderes e dos saberes.

Palavras-chave: Foucault. Baudelaire. Dandismo. Cuidado de si.
\end{abstract}

\section{O Baudelaire de Foucault: levantamento das referências}

No curso de Foucault no Collège de France, em 1982, A Hermenêutica do sujeito, há duas referências a Baudelaire:

\footnotetext{
${ }^{1}$ Texto apresentado no Séminário «Le Baudelaire des philosophes » (O Baudelaire dos filósofos), Aqui e alhures, Associação por uma filosofia nômade, Montigny-sur-Canne (Nièvre), 01 e 02 de outubro de 2011. Sua versão escrita e modificada é inédita em lingua francesa. Agradecemos ao autor a gentileza de nos autorizar a publicação da tradução em português desse seu artigo feita pelo professor Pedro de Souza, da Universidade Federal de Santa Catarina.

* Philippe Chevallier é doutor em filosofia, trabalha na Biblioteca Nacional da França. É autor dos livros Michel Foucault, le pouvoir et la bataille, Nantes, Plein Feux, 2004; Etre soi, Actualité de Søren Kierkegaard, Paris, François Bourin, 2011; Michel Foucault et le christianisme, Lyon, ENS éditions, 2011.

${ }^{2}$ Foucault M., As Palavras e as Coisas. Uma arqueologia das ciências humanas. Tradução Salma Tannus Muchail. São Paulo Martins Fontes, 2000.

${ }^{3}$ No dicionário de Antônio Houaiss, a palavra remanência designa o magnetismo que permanece em um eletroímã, mesmo após terem cessados os efeitos da força elétrica que atuou sobre ele. Chevallier emprega o termo como metáfora das repercussões de Baudelaire que permanecem atraindo a atenção de artistas mesmo depois de cessar as forças históricas diretamente relacionadas à sua atitude (nota do tradutor).
} 
- Uma primeira referência indireta, com a menção do «dandismo moral» ${ }^{4}$. Esta referência representa o papel de figura propulsora: ela designa a falsa interpretação que se poderia ter da noção antiga de «cuidado de si». O cuidado de si, no sentido que lhe confere, por exemplo, a filosofia estoica, não é redutível a um «estágio estético» do desafio e da exibição, destinada a ser ultrapassada uma vez tocado o fim do recreio ${ }^{5}$, ainda menos a uma dobra sobre si. O cuidado de si é uma atividade regrada e exigente, mãe das morais mais austeras e restritivas. Notemos que Foucault faz referência aqui apenas ao sentido mais comum, mais pobre, da palavra «dandismo».

- Uma segunda referência direta. Depois de ter ressaltado que a posteridade do cuidado de si na cultura moderna era ambígua e, por vezes, contraditória, Foucault nota entretanto: «Mas podemos reler toda uma vertente do pensamento do século XIX como a difícil tentativa, ou uma série de difíceis tentativas, para reconstituir uma ética e uma estética do eu. ${ }^{6} »$. E Foucault cita: «Stirner, Schopenhauer, Nietzsche, o dandismo, Baudelaire, a anarquia». Dois elementos merecem ser levantados nesta proposição, a fim de lhe traçar o perímetro preciso: prefixo re- do verbo «reconstituir» indica que uma ética de si se perdeu no entre-tempo; o adjetivo «dificil» que qualifica o termo «tentativa» deixa em suspenso a questão de saber se este esforço para reconstituir uma ética de si no período moderno foi coroado de êxito, se foi exemplar, até mesmo pertinente (Foucault não se pronuncia sobre a vitória da empresa).

Observemos agora um dos últimos grandes artigos de Foucault «O que são as luzes? », texto do qual há três versões diferentes, das quais apenas a segunda, publicada no início de 1984 em Foucault Reader, faz menção a Baudelaire ${ }^{7}$, - menção aliás relativemente breve. Esse texto trata da definição da atitude crítica como relação ao presente, atitude da qual Foucault encontra no opúsculo de Kant do mesmo nome (Was ist Aufklärung?, 1784) uma formulação exemplar e quase-matricial. O comentário desse texto de Kant abria já o curso de

\footnotetext{
${ }^{4}$ Foucault M. A Hermeneutica do sujeito. tradução Marcio Alves da Fonseca, Salma Tannus Muchail. São Paulo: Martins Fontes, 2004, p. 16.

${ }^{5}$ Referência aqui de Foucault ao estágio estético de Kierkegaard, considerado ultrapassado pelo estágio ético, depois religioso.

${ }^{6}$ Foucault M., A Hermêutica do sujeito, op. cit., p. 305.

${ }^{7}$ Foucault M., «What is Enlightenment?», in The Foucault Reader, éd. P. Rabinow, New York, Pantheon Books, 1984 ; texte français : "Qu'est-ce que les Lumières ? », Dits et écrits, t. 2 : 1976-1988, éd. D. Defert et F. Ewald, Paris, Gallimard, «Quarto », 2001 ( $1^{\mathrm{e}}$ édition, 1994), p. 1381-1403; Tradução brasiliera : O que são as Luzes? In. _ _ Ditos e escritos - arqueologia das ciências e história dos sistemas de pensamento. Vol. II. Rio de Janeiro: Forense Universitária, 2000, p. 335-351. É muito provável que a referência a Baudelaire tenha sido acrescentada por Foucault para se remeter a um público universitário americano, conhecedor dos escritos de Walter Benjamin sobre o poeta francês. Em um gesto discretamente polêmico, tratar-se-ia de «arrancar» Baudelaire de Benjamin e da escola de Francfort, muito influente em alguns campos.
} 
1983 no Collège de France, O governo de si e dos outros, e será retomado em maio de 1984 em um artigo para o Le Magazine littéraire, mas sem a referência a Baudelaire.

Se se lê esse texto de perto reaproximando dele as reflexões anteriores de Foucault sobre crítica $^{8}$, algo de muito notável e de muito novo aí aparece. O entrecruzamento dos temas desenvolvidos a partir de Kant e das próprias reflexões de Foucault sobre as condições de ação política contribui para fazer da atitude crítica nem mais nem menos que um uma invariante histórica. A atitude crítica não é uma posição particular mas a condição de possibilidade de toda posição, que Foucault identifica em uma entrevista de 1984 na atividade mesmo do pensamento, em uma definição ao mesmo tempo simples mas firme: «O pensamento não é o que habita uma conduta e lhe dá um sentido; ele é sobretudo o que permite tomar distância em relação a esta maneira de fazer ou reagir, de se tomá-la como objeto de pensamento e de a interrogar sobre seu sentido, suas condições e fins» ${ }^{9}$. Mesmo se se trata aqui de uma ontologia minimal, voluntariamente elementar, ela tem o mérito de fornecer uma resposta à questão por demasiado tempo deixada em suspenso das condições de possibilidade do próprio trabalho histórico, filosófico e político de Foucault.

\section{Atitude de modernidade como realização da atitude crítica}

Desta atitude crítica, Foucault faz então «o esboço da atitude de modernidade» ${ }^{10}$, que é preciso entender como um desenvolvimento, até uma realização singular da primeira - o que verifica bem o termo «esboço»: a modernidade como obra acabada da crítica. A modernidade não designa primeiro um período histórico, mas uma maneira de ser, no sentido forte de um êthos: um comportamento regular, um caráter. Este êthos se compõe para Foucault de três elenentos: 1) «um modo de relação a respeito da atualidade»; 2) «uma escolha voluntária»; 3) «uma maneira de agir e de se conduzir que, ao mesmo tempo, marca uma pertença e se apresenta como uma tarefa» ${ }^{11}$. Não pode portanto religar a modernidade a um momento histórico particular: se pode ser anti-moderno na época dita moderna e, inversamente, é preciso revisar a maneira com que os historiadores falam de uma prémodernidade

\footnotetext{
${ }^{8} \mathrm{Cf}$. em particular a primeira menção por Foucault desse texto de Kant: «Qu'est-ce que la critique? » (sessão de 27 de maio, 1978), Bulletin de la société française de philosophie, t. 84, 1990, p. 35-63.

${ }^{9}$ Foucault M., «Polémique, politique et problématisations», Dits et écrits, t. 2, op. cit., p. 1416.

${ }^{10}$ Foucault M., «O que são as luzes? », Ditos e escritos, op. cit.

${ }^{11}$ Foucault M., «O que são as luzes? », Ditos e escritos, op. cit.
} 
Novamente, esta definição da atitude de modernidade toma uma dimensão transhistórica que poderia parecer provocativa aos olhos da concepção foucaultiana «descontinuista» da história, a definida, por exemplo, em As palavras e as $\operatorname{coisas}^{12}$. O outro grande exemplo, na obra de Foucault, do ressurgimento através da história de uma mesma atitude individual será o cinismo, no curso $A$ coragem da verdade em 1984: «A doutrina cínica portanto, de algum modo, desapareceu, Mas isso quer dizer que o cinismo [...] não se transmitiu, não continuou e prosseguiu essencialmente como uma atitude, uma maneira de ser, muito mais que como uma doutrina?» ${ }^{13}$. Se a história ocidental dos saberes é escandida por grandes rupturas, não acontece o mesmo com a história das atitudes subjetivas. Sem dúvida porque a subjetividade é nela mesma essa perpétua possibilidade da repetição ${ }^{14}$ reflexo do que se disse, se pensou, e se viveu no passado.

A fim de dar um exemplo histórico preciso de tal «atitude de modernidade», Foucault se se volta então para Baudelaire - não o poeta mas o pensador, o ensaista, através do comentário de um único texto: «O pintor da vida moderna». Este ensaio, redigido por Baudelaire em 1859-1860, é composto de três artigos elogiando o trabalho do caricaturista Constantin Guys (1802-1892). Foucault tira daí quatro caractéristicass da atitude de modernidade em Baudelaire, beseadas em citações específicas:

1. Heroicizar o presente: não desprezá-lo, não fugir dele, mas tomar o que se representa de essencial nesse presente (por exemplo : a relação com a morte figurada por um certo uso de vestuário sombrio no pintor moderno). O presente deve ser o canto enterrado em uma temporalidade feita de brechas, de buracos, de falhas; uma temporalidade incerta, descontínua.

2. Mas é preciso heroicizá-lo ironicamente, ou seja, não sacralizá-lo, nem lhe testemunhar espécie de fascinação passiva. Não se pode apenas olhá-lo ou reproduzi-lo tal como ele é, é preciso transfigurá-lo. «[...] o alto valor do presente indissociável da fúria a imaginá-lo, a imaginá-lo de modo diferente do que ele é e a transformá-lo não o destruindo, mas o capturando nisso que ele é» ${ }^{15}$. É preciso ao mesmo tempo respeitar o real e violá-lo; retirar por exemplo o que a moda pode «conter de poético no histórico» ${ }^{16}$.

\footnotetext{
${ }^{12}$ Foucault M., As palavras e as coisas, op. cit., p. XVIII : «A ordem, sobre cujo fundamento pensamos, não tem o mesmo modo de ser que a dos clássicos».

${ }^{13}$ Foucault M., A coragem da verdade. O governo de si e dos outros II. Curso no Collège de France, 19831984. Editora Martins Fontes, 2011, p. 156.

${ }^{14}$ Seria preciso entender repetição em seu sentido kierkegaardiano: Kierkegaard S., Gjentagelsen (Repetição), 1843.

${ }^{15}$ Foucault M., «O que são as luzes?», Ditos e escritos, op. cit..

${ }^{16}$ Baudelaire citado em Foucault M., «O que são as luzes?», Ditos e escritos, op. cit..
} 
3. Duplicar a relação com o presente com uma relação a si mesmo, que Foucault qualifica «ascese»: «[...] tomar a si mesmo como objeto de uma elaboração complexa e dura» ${ }^{17}$, eis o que é para Baudelaire, relido por Foucault, o «dandismo». Trata-se de fazer «de sua existência uma obra de arte», o dandi sendo aquele «que busca se inventar a si mesmo».

4. Esses três gestos singulares encontram sua realização em um lugar singular que se chama arte : «Esta heroicização irônica do presente, esse jogo da liberdade com o real para sua transfiguração, esta elaboração ascética de si, Baudelaire não concebe que elas possam ter lugar na própria sociedade ou no corpo político. Eles não podem se produzir senão em um lugar outro que Baudelaire chama arte ${ }^{18}$. Não se trata aqui, bem entendido, apenas das obras de arte.

\section{Historicidade e remanência}

É, sem dúvida, nesse artigo de Foucault que pensa o historiador Pierre Hadot quando critica a estética da existência foucaultiana, que confundiria o cuidado de si antigo com uma nova forma de «dandismo» ${ }^{19}$. Dizendo isso, Hadot mostra de passagem que não conhece o curso Hermenêutica do sujeito, que bastaria para fazer cair a maior parte dessas objeções. Mas pouco importa: Hadot sentiu bem que havia aí um ponto crítico na obra de seu colega e amigo. O imbricamento dos temas dos quais Baudelaire é aqui a ocasião se revela efetivamente tão fascinante quanto pertubadora. Em Baudelaire e sua modernidade, Foucault cruza:

- Caractéristicas 3 e 4: dos temas desenvolvidos no mesmo momento por Foucault a respeito da Antiguidade greco-romana. Reencontramos efetivamente a concepção de si-mesmo como obra de arte, desenvolvida por Foucault a partir da Antiguidade grega ${ }^{20}$, e esta ideia estranha, problematizada a partir do estoicismo romano, que o cuidado de si é ora político, ora socialidade, mesmo se ele interagia sem cessar com eles ${ }^{21}$.

\footnotetext{
${ }^{17}$ Foucault M., «O que são as luzes?», Ditos e escritos, op. cit..

${ }^{18}$ Foucault M., «O Que são as Luzes?», Ditos e escritos, op. Cit. p. 342.

${ }^{19}$ Hadot P., La Philosophie comme manière de vivre, entretiens avec J. Carlier et A. Davidson, Paris, Albin Michel, 2002, p. 214-215.

${ }^{20}$ Foucault M., «À propos de la généalogie de l'éthique: un aperçu du travail en cours», Dits et écrits, t. 2 : 19761988, p. 1221 (version initiale) ; 1443 (version ultérieurement revue). Tradução brasileira: FOUCAULT, Michel. Sobre a genealogia da ética: uma visão do trabalho em andamento. In.: ESCOBAR, Carlos Henrique de. (Org.). Michel Foucault: O dossier - últimas entrevistas. Rio de Janeiro: Taurus, 1984. p. 49-50.

${ }^{21}$ Tema longamente desenvolvido em um texto inédito (dossier «Gouvernement de soi et des autres »): Foucault M., FOUCAULT, Michel. A Hermenêutica do sujeito. São Paulo: Martins Fontes, 2004. p. 520-521.
} 
- Característica 1 : uma relação ao presente que é justamente aquele previamente descrito no artigo, a partir de Kant. Trata-se de pensar esse momento das Luzes sem fazer uma nova aurora, pensar simplesmente esta diferença que é o agora no seio de uma história descontinua.

- Característica 2: uma noção de transfiguração que junta a própria relação de Foucault ao real descrito em uma entrevista publicada em 6 de abril de 1980 no Le Monde: «A palavra [curiosidade] evoca o cuidado que se toma o que existe e o que poderia existir; um sentido agudo do real mas que não se marca diante dele; uma prontidão a achar estranho e singular o que nos rodeia; um certo impulso a nos desfazer de nossas familiaridades e a olhar de outro modo as mesmas coisas; um ardor a tomar isso que se passa e o que passa; uma desenvoltura a respeito das hierarquias tradicionais entre o importante e o essencial. Sonho com uma era nova da curiosidade. ${ }^{22}$ Ver portanto o real, mas vê-lo de tal maneira que ele possa ser mudado - da mesma maneira que Foucault não hesitava em fazer jogar a ficção no real histórico para o tornar mais político, mais perigoso.

Este imbricamento de períodos e referências faz juntar audaciosamente a Antiguidade e a modernidade. Algo dura, perdura em certa atitude diante de si e diante do presente do qual Foucault traça repetidamente genealogias rápidas, através de seus cursos, artigos e entrevistas dos últimos anos: de Sêneca a Montaigne e Descartes (para a filosofia como exercício espiritual); depois para Kant, Hegel e Nietzsche (para o cuidado do presente); e enfim Stirner, Baudelaire, Schopenhauer (para o cuidado de si). Genealogias hesitantes, entretanto, pois a história foucaultiana marca no mesmo movimento as rupturas e as difíceis retomadas.

Baudelaire torna-se assim o nome próprio dessa possível junção; e ele vem estranhamente duplicar a referência a Kant que teria podido aqui bastar - dobra inesperada, e em parte provocante se se lembrasse que o contexto dela é uma crítica da arte, comentantando gravuras de moda e de croquis de costumes onde está em questão ornamentos, costumes, cortinados, ali onde o êthos antigo é primeiro essencialmente pensado, presença a si, logos e desnudamento.

O texto de Baudelaire não pode senão perturbar e fascinar Foucault, pela maneira com que permite estranhas reaproximações e incessantes desligamentos. Citemos Baudelaire

\footnotetext{
${ }^{22}$ Foucault M., « Le philosophe masqué », Dits et écrits, t. 2 : 1976-1988, p. 927.
} 
em «O pintor da vida moderna» ${ }^{23}$ : «Vê-se que, sob certos aspectos, o dandismo assemelha-se ao espiritualismo e ao estoicismo» (mesmo se Baudelaire dá a esse termo um sentido trivial) ; ele pratica «o culto de si-mesmo»; «uma ginástica apta a fortificar a vontade e a disciplinar a alma». Estamos ao mesmo tempo tão longe e tão próximo dos esforços de Foucault para definir, a partir da Antiguidade greco-romana, uma ética de si: «Esses seres não têm outro estado que cultivar a idéia do belo na pessoa deles» (e Baudelaire precisar que não se trata apenas de toilettes e de aparência); mas eles revelam também tendências mais folgosas, até mesmo desornadas, como a «de satisfazer suas paixões» e de se afirmar em sua originalidade própria: «[...] todos participam do mesmo caráter da oposição e da revolta; todos são representantes do que há de melhor no orgulho humano, dessa necessidade, demasaiado rara, nos dias de hoje, de combater e de destruir a trivialidade.» $\mathrm{O}$ dandi não é o sábio antigo: ele é assimilado por Baudelaire às figuras de César, Catilina («um grande vigor intelectual e físico, mas mas uma lama ruim e depravada») ou ainda Alcibiades (e não Sócrates, Marco Aurélio ou Sêneca!).

Esse levantamento de semelhanças e diferenças permite inserir o dandi nesta «série de tentativas difíceis para reconstituir uma ética e uma estética do si», se levarmos em conta que esta série implica forçosamente deslocamentos, estranhezas e derivas múltiplas. Precisamente porque esta remanência não repousa sobre nada mais que a capacidade de recepção e de invenção misturadas do que se testemunha a subjetividade na história.

[Recebido em agosto de 2012 e aceito para publicação em novembro de 2012]

\section{Le Baudelaire de Foucault : une silhouette furtive et paradoxale}

Resumé: Personnage fuyant, le Baudelaire de Foucault a une vie à la fois brève et remarquable. Brève, car un unique texte en 1984 lui offre un espace d'expression conséquent. Remarquable, car ce texte est l'occasion d'un déplacement important des propres présupposés philosophiques de Foucault sur les rapports de la subjectivité à l'histoire. À rebours d'un découpage de l'histoire en périodes radicalement hétérogènes, tel que le présente par exemple Les Mots et les Choses en 1966 , la silhouette de Baudelaire dessine la possibilité de la rémanence, à travers des ères culturelles distinctes, d'une même attitude subjective - preuve que l'histoire de la subjectivité ne connaît pas les mêmes cassures que l'histoire des pouvoirs et des savoirs.

Mots-cle: Foucault.Baudelaire. Dandysme. Souci de soi.

\footnotetext{
${ }^{23}$ Esse texto foi inicialmente publicado em três edições do jornal Le Figaro: 26 e 29 de novembro, 3 de dezembro 1863. Tradução brasileira : BAUDELAIRE, Charles. Sobre a modernidade. São Paulo Editora Paz e Terra, 1996.
} 


\section{Furtive silhouette, the Baudelaire of Foucault}

Abstract: Furtive silhouette, the Baudelaire of Foucault has a short and remarkable life at the same time. Short, because a unique text in 1984 offers him a consequent space of expression. Remarkable, because this text is the occasion of an important shift in the philosophical pressupositions of Foucault about the relationships between subjectivity and history. Against a division of history in radically heterogeneous periods, such as exposed for example in "The Order of Things" in 1966, the silhouette of Baudelaire draws the possibility of remanence, through distinct cultural eras, of the same subjective attitude - proof that the history of subjectivity does not know the same breaks as the history of powers and knowledge.

Keywords: Foucault. Baudelaire. Subjectivity

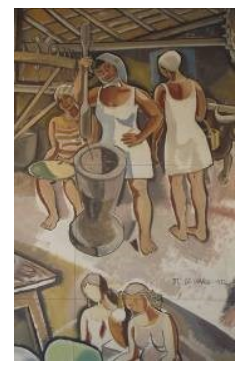

